Utah State University

DigitalCommons@USU

Marketing and Strategy Faculty Publications

Marketing and Strategy

$10-31-2019$

\title{
Strategies that Male Allies use to Advance Women in the Workplace
}

Susan R. Madsen

Utah State University, susan.madsen@usu.edu

April Townsend

Utah Valley University

Robbyn T. Scribner

Follow this and additional works at: https://digitalcommons.usu.edu/marketing_facpub

Part of the Marketing Commons

\section{Recommended Citation}

Madsen, S. R., Townsend, A., \& Scribner, R. T. (2019). Strategies that male allies use to advance women in the workplace. Journal of Men's Studies. https://doi.org/10.1177/1060826519883239

This Article is brought to you for free and open access by the Marketing and Strategy at DigitalCommons@USU. It has been accepted for inclusion in Marketing and Strategy Faculty Publications by an authorized administrator of DigitalCommons@USU. For more information, please contact digitalcommons@usu.edu.

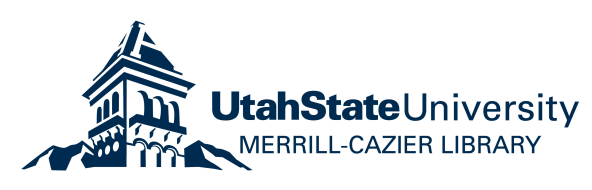


Strategies that Male Allies Use to Advance Women in the Workplace

\author{
Susan R. Madsen \\ April Townsend \\ Robbyn T. Scribner \\ Utah Valley University
}

For Publication in the Journal of Male Studies 


\begin{abstract}
The purpose of this research study was to identify and examine, from both men's and women's perspectives, the specific behaviors and strategies male allies use to successfully support the advancement of women in workplace settings. The team gathered qualitative survey data from 243 men and women which were analyzed to identify the strategies and behaviors used by male allies. Top responses included developmental relationships, human resource (HR) processes, leadership development, recognition (both public and private), treating women as equals, and challenging sexist behavior. Some differences existed between perceptions of men and women in terms of the most critical ally behaviors. These research findings have scholarly and practical implications in future efforts to work toward greater gender parity.
\end{abstract}

Keywords: Male Allies, Women's Leadership, Women's Advancement, Gender Equity, Lessons of Experience

Acknowledgement: We would like to thank Michelle Taylor for her work during the analysis stage of this research. 
Strategies Male Allies Use to Advance Women in the Workplace

Over the last several decades, academic research and the popular press have brought attention to the lack of gender parity in the workforce (Madsen \& Scribner, 2017). While progress has been made at increasing the number of women in entry-level and lower-level management positions, men continue to dominate the upper echelons of organizations and retain the most powerful positions, leaving women consistently underrepresented or completely absent from senior leadership teams (Bowers, 2016; Cheng, Ng, Trump-Steele, Corrington, \& Hebl, 2018; Krentz, Wierzba, Abouzahr, Garcia-Alonso, \& Taplett, 2017; Sawyer \& Valerio, 2018). Current statistics show women hold only $4 \%$ of CEO positions in the S\&P top 500 companies, despite being just as ambitious and educated as men (Sawyer \& Valerio, 2018). When an organization's top leadership is dominated by a singularly consistent set of workplace and life experiences (that of White men), it unintentionally creates a talent blind-spot that reduces the organization's agility to adapt to a constantly changing environment and results in missed opportunities (Krentz et al., 2017; Prime \& Moss-Racusin, 2009).

Business are failing to realize the strategic benefits of including women in their leadership teams (Center for Women and Business, 2017). Research has positively correlated the diversity of an organization's leadership team with more diverse perspectives, resulting in better strategic decisions, increased capacity for problem solving, more resilience and innovation, and increased ability to adapt to change (Catalyst Information Center, 2013; Center for Women and Business, 2017; Sawyer \& Valerio, 2018). These elements are critical to the survival of modern organizations in an ever-changing environment (Krentz et al., 2017). Simply stated, "women are good for business," (Prime \& Moss-Racusin, 2009, p. 2). 
While some organizations have instituted programs intended to increase the number of women leaders, progress has stalled, and many firms are seeing their gender-parity initiatives falling short of intended goals (Sherf, Tangirala, \& Weber, 2017; Warner \& Corley, 2017). These initiatives often focus on changing women, from how they communicate to the way they lead (Prime \& Moss-Racusin, 2009). This approach has the unfortunate side-effect of positioning gender diversity in top leadership as a "women's issue," rather than framing it as part of a larger conversation that impacts the overall success and performance of the company.

By treating gender inequity as a problem for women to solve, organizations have also unintentionally alienated men while creating a dynamic that fails to acknowledge and change the very "organizational practices that maintain the status quo" (Prime \& Moss-Racusin, 2009, p. 2). There are too few women leaders to effect meaningful change alone, and since men constitute most of an organization's leadership, their involvement is critical. By working together, men and women can transform their workplaces to ensure diversity and gender parity are valued (Cheng et al., 2018; Krentz, et al., 2017; Prime \& Moss-Racusin, 2009; Sherf et al., 2017). Although many men understand and embrace the "business case" for women in management and leadership, they lack effective strategies they can use in workplace settings to advance women (Center for Women and Business, 2017). To address this deficit, the purpose of this research study was to explore, from both men and women's perspectives, specific behaviors and strategies men have used to successfully support the professional development and advancement of women.

\section{Literature Review}

Available scholarly literature on male allies in the workplace is extremely limited. While there are publications that emphasize the importance of men's involvement, they are found in 
popular, trade, and industry publications, yet these publications lack the research to support how those strategies play out in the workplace. Regional research has tried to fill that gap by providing strategies men can use to help advance women (e.g., Johnson \& Smith, 2018; Madsen, Townsend, \& Scribner, 2019; Scribner \& Madsen, 2018; Van Velsor \& Hughes, 1990). After highlighting available literature on male allyship, we present a conceptual framework that guided our research and provided insight into our data analysis.

\section{Critical Nature of Men's Involvement}

Men hold a majority of the most powerful roles and positions in organizations, yet their voices are "noticeably absent" from the conversations about women in leadership (Sherf et al., 2017, p. 194). While men have not traditionally been seen as supporters of women's advancement, changes in the business world — and the current social and political climate — have brought more attention to gender equality and the need for male allies in the workplace (Cheng et al., 2018). Because men are the largest and most influential stakeholder group, their involvement and promotion of gender-parity initiatives are imperative (Center for Women and Business, 2017; Prime \& Moss-Racusin, 2009; Sherf et al., 2017).

Data from the Boston Consulting Group Gender Diversity Survey showed that "among companies where men are actively involved in gender diversity, 96\% report progress. Conversely, among companies where men are not involved, only $30 \%$ show progress" (Krentz et al., 2017, p. 2). Framing gender-parity initiatives in a way that encourages men to contribute to the solution engages those who have the social capital and organizational power (standing) to actually make a difference (Sawyer \& Valerio, 2018; Sherf et al., 2017). As men in the workplace become allies and are willing to speak out against gender bias and prejudice, they can play a pivotal role in creating a gender-inclusive environment (DuBow \& Ashcraft, 2016). 


\section{Men and Allyship}

Historically, allyship research literature has focused on social justice advocacy or men's antiviolence gender-equity work (Anicha, Burnett, \& Bilen-Green, 2015). Theoretical models of allyship within this context have two main features: first, allies are aware of the power they have as a member of a dominant social group and the related injustice experienced by those who are oppressed by the dominant social group; and second, they have a sense of accountability for the injustice and take intentional action to interrupt sexism or gender injustice.

More recently, the theory of allyship has been linked to having a positive impact within the workplace (Sawyer \& Valerio, 2018). Although advocating for gender equity within an organization is considerably different than antiviolence work, there are certainly similarities as men recognize and are willing to confront bias (DuBow \& Ashcraft, 2016). According to Sawyer and Valerio (2018), “Allies may be able to enact change within organizations and their mere presence has been demonstrated to have a positive impact on those who have historically faced bias at work" (p. 2).

Research on the theory of allyship has included a variety of terms, including advocates, champions, change agents, mentors, sponsors, or organizational catalysts (Drury \& Kaiser, 2014; Sue, 2017; Smith \& Johnson, 2017). Although definitions vary slightly, the essence of allyship comes through supporting the members of a disadvantaged group, even when a member of that group is not in the room (Center for Women and Business, 2017). Research has framed allyship as being a part of the dominant group, which provides allies with the ability to draw on social capital not available to marginalized individuals that can then be leveraged to create equity for marginalized groups (Anicha et al., 2015; Cheng et al., 2018; Peretz, 2018). This is particularly true for White men, who are the most entrenched demographic within the corporate environment 
and who are "uniquely immune from backlash when advocating on behalf of others" (Cleaver, 2016, p. 1).

Research relating the theory of allyship to corporate settings shows male allies have distinct opportunities to be influential advocates to create change in gender inclusion efforts (Cheng et al., 2018; Prime \& Moss-Racusin, 2009). As mentioned earlier, the theory of allyship requires a member of the dominant group to take intentional action to interrupt sexism or gender injustice. As men increasingly challenge sexist behaviors, researchers are documenting the impact their actions are having on changing the attitudes of other men, while also providing examples of positive actions men can take (Casey et al., 2013, DuBow \& Ashcraft, 2016; Piccigallo, Lilley, \& Miller, 2012; Sawyer \& Valerio, 2018; Swim \& Thomas, 2006).

Czopp and Monteith (2003) discovered that when men confronted perpetrators of sexism, the perpetrators felt the negative feedback was more legitimate and therefore felt more guilt for their actions than if they had been confronted by a woman. Rasinski and Czopp (2010) found that men received fewer negative responses when they pointed out gender bias and prejudice, which suggests that as male allies confront sexism, they will likely be perceived as expressing a more legitimate and appropriate response. Thus, it costs men less social capital than women to confront sexism, and men will likely receive less backlash than women who challenge the same behaviors (Drury \& Kaiser, 2014).

The theory of allyship has found that in general, not only do men risk less in challenging sexism, but their confrontations could contribute to changing attitudes about the acceptability of gender prejudice and bias (Drury \& Kaiser, 2014). Publicly challenging sexist behaviors could create a domino effect, where others are subsequently empowered to confront inappropriate behaviors or comments (Swim \& Thomas, 2006). According to Drury and Kaiser (2014), “As 
such, by publicly opposing sexism, men may be especially able to decrease the perceived acceptability of sexist behavior, while also encouraging others to take action against such acts" (p. 644).

\section{Conceptual Framework}

The conceptual framework used for this study was from the Center for Creative Leadership (CCL)'s Lessons of Experience (LOE) research. Experiences are commonly recognized as critical for adult learning (Hezlett, 2016), come in many shapes and sizes (McCauley \& McCall, 2014), and are the foundation of career and leadership development. The LOE research was based on "interviews with hundreds of executives who were asked to reflect on key experiences and events that led to a lasting change on how they lead and manage, and what they learned from those experiences and events" (p. 378). This approach has been widely championed and embraced by both private and public sectors (Johnson, Blackman, \& Buick, 2018). The framework is helpful for male allies' research as it compares the experience of both men and women, is based on leaders' retrospectives, and has been utilized and validated across cultures and generations (McCall, Jr., Lombardo, \& Morrison, 1988; Van Velsor, Wilson, Criswell, \& Chandrasekar, 2013; Yip \& Wilson, 2010). It also provides insight into the most important experiences needed to advance in workplace settings and offers a framework for data analysis, as we will discuss later.

According to Clerkin and Wilson (2017), the LOE includes five categories of experiences that support leadership development: (1) challenging assignments, (2) developmental relationships, (3) courses and training programs, (4) hardships, and (5) personal experiences. The first three categories have been grouped and labeled as the "70-20-10 framework," a guideline for the percentages on which a company should focus its leadership development efforts with 
$70 \%$ focused on challenging assignments, $20 \%$ on developmental relationships like coaching or mentoring, and 10\% on formal training (McCauley \& McCall, 2014). Although some research has found that women report fewer lessons learned from challenging assignments and training, and more from developmental relationships and hardships (Van Velsor \& Hughes, 1990). Of course, this all must be considered in terms of the fact that many leadership studies, including the one mentioned above, are skewed in favor of males, both in the numbers of participants studied and the male-normed theories guiding the research itself (Storberg-Walker \& Madsen, 2017).

Brief descriptions of the five LOE categories of experiences that support leadership development are as follows:

1. Challenging assignments are defined as an expansion in scope of current responsibilities which results in an individual struggling and stretching beyond his or her current abilities (Yip \& Wilson, 2010). Examples include job rotations, working in a different culture, horizontal moves, promotions or increase in job scope, new initiatives, stakeholder engagement, turnaround and fix-it tasks, or any other special assignment that provides an individual with opportunities to grow (Clerkin \& Wilson, 2017). Unfortunately, access to these opportunities continues to be a challenge for women.

2. Developmental relationships comprise the second-most frequently cited leadership learning experiences in LOE research. These relationships include "relational feedback, coaching, one-on-one mentoring, and peer and group mentoring” (Yip \& Wilson, 2010, p. 73). Research has suggested that there are gender differences regarding access to and opportunities for developmental relationships. For example, Carter and Silva (2010) found that men's mentors tended to be more senior, and that 
senior mentorship was linked to promotion, while Hewlett's (2013) work emphasized that women have fewer sponsors than men.

3. Coursework and formal training programs have been shown to help individuals advance their careers through attending development/training programs to facilitate learning, growth, or career progress (Clerkin \& Wilson, 2017). Examples range from in-house formal management development programs and experiential workshops to academic programs, international study, and executive education courses (McCall, Jr., Lombardo, \& Morrison, 1988). Since more men occupy management positions, men have greater access to leadership development coursework and programs. In addition, researchers have found that leadership trainings and content are still largely designed with men in mind and focus on masculine approaches to leadership (Clerkin \& Wilson, 2017). This has prompted scholars to argue that female-only leadership development programs are necessary for women to progress in substantial ways (Debebe, Anderson, Bilimoria, \& Vinnicombe, 2016; Ely, Ibarra, \& Kolb, 2011; Madsen, 2017; Ngunjiri \& Gardner, 2017; Sugiyama et al., 2016).

4. Hardships often emerge from "unfortunate and unforeseen situations that are beyond the control of the organization and individuals" (Clerkin \& Wilson, 2017, p. 385), and are viewed as transformative because they can provide development (e.g., "defining moments," "leadership crucibles," and "transformational moments") (Badaracco, 1997; Bennis \& Thomas, 2002; Madsen, 2009). Madsen (2008a, 2008b) found that failures and challenges were central to the growth and development of female leaders. Clerkin and Wilson (2017) surmise that "women and men may learn different lessons from hardship, and that these lessons could impact their leadership effectiveness and 
career choices in different ways" (p. 386). They also reported that hardships often described by men related to group- or organizational-level challenges, while women's hardships seem to be related to individual-level struggles to advance, particularly those that were gender based.

5. Personal experiences comprise the final component of the LOE model. These experiences encompass happenings early in life, family situations, early job experiences, leadership opportunities, spiritual encounters, and more that influence a person's values and behaviors (Van Velsor et al., 2013). Key personal experiences are times when values are formed and life direction shifts, and they are influenced by gender. Research shows that leaders internalize valuable leadership lessons throughout their lives, not just in the workplace (Madsen, 2008a, 2008b; Van Velsor \& Hughes, 1990). For example, Madsen (2008a, 2008b) and Clerkin and Wilson (2017) found that women can gain profound leadership learning from personal experiences, including volunteering, motherhood, community initiatives, and church leadership.

These five categories of experiences, combined with the theory of allyship, provide the conceptual framework to discuss the results of the research study.

\section{Research Methods}

This study draws on qualitative data collected during July and August of 2018 through a web-based survey tool. After Institutional Review Board approval, participants were recruited through a monthly women's initiative newsletter, as well as through Chambers of Commerce and women's networks or organizations within the state of Utah. We received 461 responses and were able to utilize the 243 completed surveys for the qualitative analysis, with $163(67.1 \%)$ 
women and $80(32.9 \%)$ men responding. The number of respondents meant this study is one of the largest on this topic to be conducted and published with working adults.

In terms of demographics, the age of participants was spread fairly equally among those in their 20s (21.2\%), 30s (26.9\%), 40s (26.1\%), and 50 and older (25.8\%). Most of the participants had bachelor's degrees (36.7\%) or master's degrees and higher (55.3\%). Further, $74.6 \%$ of those who answered the demographic questions self-identified as married, $88.5 \%$ as Caucasian, and $78 \%$ as members of The Church of Jesus Christ of Latter-day Saints. In terms of location, $80.2 \%$ of respondents lived in two major metropolitan areas of the state, with the remainder living in other areas. Next, $43.6 \%$ of respondents said they were in education settings, $34.5 \%$ in business, and the rest in government, nonprofit, or other types of work environments. Finally, $17.7 \%$ identified themselves as top leaders, $25.3 \%$ as managers, $35 \%$ as professionals, and $9.3 \%$ as individual contributors, supervisors, or support staff. Because this research was conducted in the State of Utah, the demographics of the state were (not surprisingly) mirrored in the demographics of the study. As a result, the sample is skewed. We acknowledge this impacts the generalizability of the study; however, we feel the results and findings are interesting and provide useful insight.

Looking at both the theory of allyship and the LOE's "70-20-10" framework, we hoped to learn whether men actively advocated and took action on behalf of women in the workplace. Specifically, we wanted to know whether men helped the development of women by identifying challenging assignments, creating developmental relationships with women, and supporting women receiving formal training. As a result, the overarching research question identified for the study was "What behaviors and strategies have men been engaged in that have been helpful in the professional development and advancement of women?" This was to uncover the ally-related 
behaviors of men taking intentional action to support activities that aligned with the LOE framework. Three survey questions were crafted based on a review of the literature, with question one being worded slightly differently for men and women:

1. MEN: In your workplace experiences, what behaviors and strategies have you engaged in that have been helpful in the professional development and advancement of women? WOMEN: In your workplace experiences, what behaviors and strategies have men engaged in that have been helpful in your professional development and advancement?

2. What other strategies and behaviors have you observed where men have supported or advanced women you know?

3. What other ideas do you have that men (peers, supervisors, managers, and leaders) could do in workplace settings to support and advance women?

The analysis of the qualitative data received from the 243 respondents included several detailed steps. First, researchers read each response multiple times and separated out key ideas or concepts identified within each response. Each key idea was then considered individually and placed in a separate spreadsheet cell. As researchers reviewed and re-aligned the key concepts, themes began to emerge and were grouped together. This process is common within qualitative research where major ideas are identified through initial analysis and then through subsequent analyses the major ideas are aggregated into themes (Creswell, 2012). All responses from participants were grouped accordingly, so all data were utilized and reviewed independently by another researcher. This process resulted in additional themes being identified. Once all key idea phrases were grouped, researchers conducted a deeper analysis of all responses grouped within each theme to explore more in-depth insights and nuances. After this final review of the data, 
tallies were made to determine the number and percentages of respondents who provided insights into each of the specific themes.

As reported previously, specific demographics were collected, which included the following: gender (we did provide an "other" option, but it was not selected by any survey respondents), age range, highest educational level, present marital status, ethnicity, workplace location, religious affiliation, current occupation, and organizational setting. In addition, the full study included a 10-question quantitative instrument not being reported in this manuscript.

\section{Findings}

To the best of our knowledge, this research approach is unique in the study of male allyship. Since there has not been a large study of this kind, we consider this work to be groundbreaking. Although we are unable to compare our results with other studies using different demographics, based on the in-depth qualitative responses, we believe the vast majority of participants were already interested in the topic and supportive of the concept of men's allyship in advancing women. Few studies have researched the difference between men's and women's perceptions. This led us to consider that providing such a comparison to be critical as well as useful in addressing the development of male allyship in the workplace. We therefore used all results from both men and women to inform our findings. For example, men who responded likely considered themselves to be allies or desired to become allies. Women who responded appeared to be a mix of individuals who already see or would like to see more men engaged in advancing women. Most study participants provided stories, lists of ideas, and other suggestions.

After answering the demographic questions, participants replied to the three open-ended questions. This section will first report the themes and insights that emerged from the responses 
of the men, followed by the responses made by women. The section discussing the women's responses also has findings comparing the differences between men's and women's responses.

\section{Men's Perceptions}

In this study, men were asked to share behaviors and strategies they used, or that they had seen other men use, that they perceived were helpful in the professional development and advancement of women in the workplace. Eighty men responded to at least one of three questions in this section of the survey, and their comments were analyzed and coded to separate unique strategies or ideas. Five primary themes, and some secondary themes, emerged from the data (in rank order of the most commonly mentioned):

1. Developmental relationships. Mentoring was by far the most significant aspect that men identified as supporting women's leadership, mentioned by $61.3 \%$ of respondents. As mentors, men would share their own leadership development stories, were available to answer questions, and expressed confidence in their female colleagues. One participant noted, "I make sure I communicate my confidence in her ability to accomplish the mission, and how well I believe she will succeed." As mentors, men would help with career planning by identifying possible advancement opportunities and encouraging women to apply for promotions.

The men recognized they could use their "clout" to ensure more representation of women. Leaders sponsored women by encouraging the organization to consider and promote more women into leadership. When powerful men modeled advocacy, people in the organization noticed, and it made a significant impact on the organizational culture. One participant shared, "You see others notice that he [a leader] is taking an interest in this area, and it causes them to also want to change." 
2. HR (Human Resources) processes. The practices and procedures that organizations use to recruit, hire, promote, and retain employees were seen as pivotal opportunities to support the advancement of women and were ranked second at 52.5\%. Survey participants frequently called out the need to be proactive in including women in applicant pools. Some noted how they had personally ensured there was a diverse list of candidates from which to fill open positions, or they made sure qualified women were among the finalists to be interviewed. One respondent stated, "I make a point to ensure I interview just as many female as male candidates for any option positions on my team." Some even decided to extend deadlines for open positions until there were enough qualified female applicants.

The gender wage gap also emerged as a theme. These men stated that they (or others they had observed) were cognizant that an intentional effort was needed by individuals and organizations to ensure gender parity in pay. In fact, one participant said, "I do a semi-annual deep dive into our compensation and one of the factors we look at is a breakdown between men and women in the same role." Some men pointed to the wage-negotiation process, recognizing this may be more difficult for women and could be a contributor to pay inequity.

Male allies also stated that they valued a balance of work and personal life. One shared that "regardless of an employee's gender, marital status, sexual orientation, etc., [. . . we all have family and need to attend to our family needs and obligations." They believed that they had adopted family-friendly practices that focused on flexibility. As a result, these allies felt they were able to better retain talented women as well as men.

3. Leadership development. Half of the respondents (50.0\%) felt a key strategy they had used to support women advancing was providing leadership development opportunities. Some ensured organizational leadership programs reserved at least $50 \%$ of the spots for women. 
Others paid for conferences or made sure women had access to training to advance their skill sets and career opportunities. They consistently encouraged women to continue pursuing their formal education, as one participant noted that "education is an undeniably important ticket to advancement."

Providing access to special projects or assignments was also considered important to women's leadership development, particularly if these assignments provided visibility and interaction with members of the organization's senior leadership. One participant noted, “the accumulation of smaller leadership experiences does more to solidify the person's leadership persona than a single, large-exposure or giant project." Intentionally targeting job assignments that provided opportunities for women to stretch or grow their skills was seen as valuable to their development and advancement, particularly when those assignments were augmented with regular coaching.

4. Recognition. Acknowledging the efforts of women was a strategy mentioned by $42.5 \%$ of the men. This included acknowledging the contributions of female colleagues on joint projects. For example, one respondent stated, "If I'm praised for something that I'm working on and I feel that I couldn't have done it without one of my female colleagues, I make sure to publicly acknowledge that." Others would intentionally invite successful women to share their stories to normalize the presence of women in leadership. They paid attention to the order of names listed for attribution of projects, reports, or academic articles, and gave appropriate credit to women.

Another component of recognition was ensuring that women's voices were heard. One ally shared that he would call out "when the perspective of a woman has not been recognized or has been repeated by a man without acknowledgement that a woman already had said 
something." These male allies would actively create situations where women would have a voice in decision-making conversations. They noticed how common it was for men to interrupt or talk over women and made a conscious effort to redress those behaviors to ensure that women had opportunities to be heard.

5. Treating women as equals. The intentional effort to treat women as equals was a point made by $37.5 \%$ of male allies. Several felt they treated men and women the same, noting it was important to them not to treat people differently because of their gender. Yet, they also realized it was sometimes necessary to help other men realize gendered biases and assumptions, such as asking the only woman in the room to take notes, or questioning a woman's ability to balance work and life (e.g., parenting) without questioning a man's ability to do the same. One participant mentioned, "I have tried to educate our senior leaders to various aspects regarding women in the workforce: unconscious bias, mentoring, development needs, analytics, etc." The men also noted how organizational culture made a difference, and they were aware of the impact gendered language and gendered management practices had on reinforcing unconscious bias against women leaders. They found it helpful when organizations openly addressed situations when anyone (man or woman) suggested that someone was incapable of doing a job because of gender.

Secondary themes. Men were also asked whether they had any other ideas that men (peers, supervisors, managers, and leaders) could use in the workplace to support and advance women. They offered the following:

- Fairness is key. A significant number of men (43.8\%) in this study noted that women in the workplace should be treated with dignity and respect. To help women participate on a level playing field, one respondent stated, "Behaviors such as fairness, openness, 
kindness, encouragement, and support should be shown to all peers, supervisors, managers, and leaders." They acknowledged that women want the same opportunities as men and suggested that managers could actively support a healthy work-life balance for all employees.

- Addressing gendered perceptions and biases. Almost a third of male respondents (31.3\%) acknowledged the important role they played in helping other men realize how their actions may be discriminating against women. They shared the need to address inherent inequities that are built into the system and call out unconscious biases that "stack the deck against women.” They felt men should be more aware of how gender impacts women's work experiences and realize advancing women is not a women's issue but rather an organizational issue. They called on companies to be more proactive by training their hiring managers to understand the impact of implicit bias on hiring decisions. These male allies also acknowledged that peers, supervisors, managers, and leaders need to take an active role in calling out bullying and patronizing behaviors to ensure that women are treated as colleagues and equals rather than as subordinates.

- Looking to the long game. Finally, $26.3 \%$ of the men pointed to the future and the overall shortage of good leaders. They called for increasing leadership diversity by investing in the development of women. They recommended that women be intentionally exposed to learning more of the business operations, how decisions are made, and how upper management evaluates business opportunities. Leaders and managers could ensure that women had equal opportunities to chair committees or taskforces, which would provide women valuable leadership experiences while also helping organizations become accustomed to seeing women in leadership roles. As one participant noted, "Leaders and 
managers need to set the tone for others in the company that women have a place in leadership."

\section{Women's Perceptions}

Women were asked to share ways men had helped them personally advance as well as behaviors or strategies they had seen men use to help other women. Of the completed surveys of female participants, 163 included answers to open-ended questions, and these were analyzed in order to determine the most relevant themes. Many behaviors and strategies mentioned by women were similar to those mentioned by men. Yet, despite the overlap, there were differences in the frequency the top themes were mentioned, in addition to some nuances in tone and varied emphases between men's and women's responses generally. This section will include the top five themes mentioned by women and then some secondary themes as well:

1. Developmental relationships. The powerful and positive influence that male allies could have as sponsors and mentors, be that from more experienced colleagues or from peers, was listed in a large majority (78.5\%) of women's responses. In addition to many of the behaviors and strategies mentioned above by male respondents, women specifically noted the benefit they received as well-connected men introduced them to individuals within their own networks. One respondent said this was "probably the most crucial and valuable" way a male ally had supported her. Women also mentioned the high-quality, "power" connections they gained with the support of male allies, including influencers and potential clients. These are elements of the role of "sponsor" rather than "mentor," which appeared to be more important to the women compared to the men respondents.

Access to honest, specific, and timely feedback was another benefit that women reported significantly more often than men. Their allies did not hesitate to give praise or correction when 
warranted, which women felt was key to their learning and growth. One participant noted, "He isn't afraid to tell me what I did poorly and helps me figure ways to address the issue." Another quality the women appreciated from male mentors was their humility and willingness to take responsibility for their own mistakes. Overall, women agreed with the men who took our survey that one of the most powerful ways male allies can advance women is through developmental relationships of various kinds and at all levels (e.g., advisor, coach, developer, encourager, mentor, role model, sponsor, and supporter).

2. Recognition. The second most frequently mentioned theme, noted by $73 \%$ of female respondents (much higher than the male respondents), was the idea that receiving recognition (both publicly and privately) from male allies was key to their professional progress. Women appreciated nominations for awards and promotions, kudos for jobs well done, and clear credit for their ideas (which can easily be overlooked in settings where women have less visibility). They appreciated men who made sure they had a seat at the table so their voices and ideas would be heard. For example, one respondent stated, "I was in a meeting with all men and my colleague noticed I had not said anything and invited me to share my opinion as well. He still promotes my opinion when I am the only woman in the room." Yet, in addition to public recognition, women also mentioned how powerful it was for men to recognize their ideas and contributions even in private settings. Several women shared feelings of validation when men really listened to them and acknowledged the value they brought to their organizations.

Related to the idea of recognition is the potential male allies have for helping women develop confidence in their professional lives. One woman said an ally supported her by "helping me see myself as the confident and capable leader I am. Women tend not to see themselves in these roles and sometimes lack the confidence.” Another said that allies had 
helped her to "see that my skills could be applied in ways I didn't even know existed." Another woman shared, "Because they believe in me, it has helped me believe in myself." Whether the recognition of women's abilities and contributions comes in public or in one-on-one settings, women acknowledged its power in their overall growth and success.

3. Challenging gender discrimination and treating women as equals. The third most common theme among female respondents was challenging gender discrimination in all forms and treating women as equals, which was mentioned by $53.4 \%$ of women in the study. A number of female respondents stated that they did not want special treatment, and that doing their job very well, being respected and advanced on their own merits, and being judged by the same standards as men was essential for lasting success. However, many comments from women mentioned personal and specific barriers they felt they must overcome in order to be in a position where they could compete on a level playing field. Men in our study also noted this in their responses, but the level of detail and frustration shared by women in telling these stories was significant.

Women's responses concerning discrimination ranged from accounts of seemingly minor slights and microaggressions to serious instances of sexual harassment. Many women reported their own personal experiences with gender discrimination and others they had witnessed. A few examples include: "be aware of the ways women are perceived as aggressive, emotional, bossy;" "don't call women crazy;" "never make a woman the butt of a joke;" and "men need to stop objectifying us." One woman stated, "Unless men truly understand how pervasive and serious a problem gender bias is, nothing will change.” Of course, women's personal experiences with gender bias will differ greatly from men's. It seemed clear from women's responses that they 
perceived these biases as being both a significant impediment to their success and confidence, as well as an important place for men to use their influence as allies.

4. Leadership/professional development. Just under half (46\%) of the women respondents mentioned leadership and/or professional development as a key strategy used by male allies, and many of the specifics they identified were also reflected in the men's responses. Women noted that men had helped them in seeking professional development opportunities, including ongoing training and higher education, and they appreciated men who advocated for them to secure the necessary resources and funding to realize these opportunities. Female respondents also recognized that men were often in the position to assign tasks and projects, and they appreciated men who gave them strategic chances to develop their skills, build their capacity, and take risks. This included presenting at conferences, co-authoring articles, or completing other critical "benchmark" activities within their own fields. Finally, numerous women mentioned how beneficial it was when male allies had given them opportunities to lead, whether within formal leadership roles, or in other, less structured settings, both within their own workplaces and beyond. One woman stated, "[He] has provided me the opportunity to find a passion for leadership in higher education and in my community."

5. HR processes. Finally, the importance of HR processes and procedures specifically designed to facilitate women's professional wellbeing was mentioned by $27 \%$ of women. Women recognized many of the same factors as men did, such as inclusive recruiting, proactive advancement efforts, and transparent, progressive salary goals. Women also noted frequently, and in some cases emphatically, how vitally important workplace policies surrounding flexible work, childcare, pregnancy considerations, and parental leave can be in retaining and advancing women. One woman mentioned that it was significantly beneficial when her company "allowed a 
flexible work schedule (e.g., telecommuting, working four 10-hour days) and also provided childcare facilities within the work building." Although such factors were also mentioned by men, the tone with which women respondents addressed these issues was much more personal, noting that these challenges usually affect women more than men, as many women bear much of the responsibility for unpaid work in families. Several women shared stories of male allies who had gone to great lengths to support them at work while they were facing challenges in their personal lives, and by so doing had made it possible for them to continue to progress professionally.

Secondary themes. In addition to these top five themes, several additional ideas emerged when women were asked if they had other thoughts about male allies in the workplace:

- Increased awareness. First, many women (20.9\%) mentioned the need to help male allies be more aware of the wide variety of issues related to women's professional success. One woman stated, "I think a lot of men really want to help women in their organization succeed, but so many of the challenges that women face are invisible to men." Women echoed and emphasized sentiments from the men about needing to be more informed on how to support women at work, stating that many men had good intentions but low awareness of gender issues and how to best address them. Some ideas included creating safe spaces for open conversations about related issues, encouraging all employees to learn more about unconscious biases, and fostering a willingness to change.

- Generational influences, work-life balance, and high expectations. Second, several women also noted an apparent generational difference when it came to male allies' support, with younger men being more likely to take it as a given that women's professional success was important. Others mentioned how beneficial it is when men 
publicly prioritize their own work-life balance and "discourage the idea that more hours equals better." Finally, several women also stated they appreciated it when men demanded the best from them, claiming "high expectations [create] a culture in which women excel."

- Lack of support. A final interesting factor was the number of women who reported (in some cases with explicit regret) that they had never received any support from male colleagues themselves or witnessed this in others. Thirteen women ( $8.0 \%$ of respondents) said they had no experience with support from men professionally, and four men $(5.0 \%)$ also said they had never helped women specifically. Conversely, there were comments from a few men $(6.3 \%)$ expressing some frustration with women's advancement efforts in general, such as, "I have found it offensive when my gender or race has been held against me in corporate trainings," and "the focus on women should not be so strong that men start to feel discriminated against."

\section{Discussion}

We realize this is a unique sample, which limits its generalizability. That being said, we offer Table 1 which highlights the top combined themes, in alphabetical order, that emerged from all participants on effective behaviors or strategies men can use to support the advancement of women in workplace settings. This tool can be used by scholars and practitioners in discussions about ways to assist in the development of male allies in the workplace who can take intentional action to advance women in leadership positions within organizations today.

$$
\text { [Insert Table } 1 \text { about here] }
$$

In circling back to the conceptual framework used for the study built on the theory of allyship and the Lessons of Experience (LOE) framework (Clerkin \& Wilson, 2017; McCauley 
\& McCall, 2014), we found men advocating for and taking action to support all five categories of experiences that encourage leadership development. At first glance, we were only expecting the first three (e.g., 70-20-10 framework), but clearly found the hardships and personal experiences were present within the workplace (we did not collect data on these categories outside the workplace). However, many of these experiences may be holding women back from advancing, and the challenge is to figure out how, based on the theory of allyship, men can take action to support women in reframing those experiences into powerful leadership development opportunities. The following includes a brief summary of the link between our findings and the LOE framework categories, and some related to both women and male allies:

1. Challenging assignments: Study participants agreed that "stretch" assignments for women are important, and the literature is clear (see Clerkin \& Wilson, 2017) that men typically get more of these experiences. We found in the data collected from women participants that male allies took action and provided opportunities and encouraged women to take challenging assignments were helpful in women's advancement. Respondents believed challenging assignments were an important element of their leadership and professional development. In addition, new assignments (e.g., a critical committee, job promotion, new lateral position, additional responsibilities) became powerful growth experiences as well.

2. Developmental relationships: Women's developmental relationships with men were critically important in advancing women in our sample. Both men and women agreed that sponsorship, mentorship, and other support relationships can and do make a substantial difference to women, particularly if they are strategic and developmental. As part of these roles, men offering public and private recognition followed the theory of allyship by 
intentionally being supportive to women's advancement efforts. It is important to note that for men, developmental relationships with women could help them increase awareness of these issues, understand and address gendered perceptions, biases, and discrimination, as well as provide advice and tools to improve their own skills and abilities in male allyship.

3. Courses and training programs: This category appeared in our data regarding both the allies and the women who were impacted by them who felt training and coursework were important elements of their leadership and professional development. It was clear in the findings that men could improve their ability to be effective allies in the workplace by increasing their awareness, skills, and knowledge related to addressing gendered perceptions and biases, challenging gender discrimination, and treating women as equals. Unconscious bias, gender bias, and strategies for men to mentor women are all important training and development focus areas for a man's own development. Women can benefit from the same training, and the literature is clear that other kinds of learning opportunities, including women's leadership development programs, can be transformational (e.g., Debebe et al., 2016; Ely et al., 2011; Madsen, 2017; Ngunjiri \& Gardner, 2017).

4. Hardships: Although many of the female participants in this study discussed hardships in the workplace, it was difficult to surmise whether those experiences had provided valuable, developmental learning experiences for them. The hardships they noted were primarily around gender discrimination, challenges with HR and gendered business policies and processes, gendered perspectives and practices, and not getting the same opportunities as men. Although the LOE model defined hardships as "unfortunate and 
unforeseen situations that are beyond the control of the organization and individuals," (Clerkin \& Wilson, 2017, p. 385), literature also shows organizations and individuals create hardships for others on things they do "control" (e.g., Bierema, 2017).

5. Personal experiences: LOE describes this category as happenings early in life and family situations, but they also include early job experiences, leadership opportunities, spiritual encounters, and other experiences that influence a person's values and behaviors (Van Velsor et al., 2013). Several female participants described transforming experiences, often negative, that made a substantial difference in their learning and growth — or lack therein (see hardship details above).

Overall, we found comments related to all five categories of experiences that support leadership development, with most being positive, but some being negative (e.g., a lack of challenging assignments, feedback, professional development opportunities).

\section{Implications to Future Research and Practice}

Clearly, male allies can enact change in an organization's culture by actively and intentionally supporting the advancement of women while influencing the attitudes and behaviors of other men (Bowers, 2016; Cheng et al., 2018; Drury \& Kaiser, 2014; Sawyer \& Valerio, 2018). Because of the critical role male allies can play to support women's advancement and to influence organization cultural change, it is prudent to understand the strategies and behaviors intentionally used by men to support women. This study has done that by providing tools male allies can use at the individual, departmental, and organizational levels. As mentioned, the findings and Table 1 provide direct implications to practice in nearly any setting where men and women work together. Our references also provide a wealth of resources that can be used to further the goal of developing more men to become allies in advancing women. 
There is a definite need for additional research on the topic of male allies in the workplace. First, research that provides additional understanding of how men learn to become allies within the context of the workplace would be very useful. This could include research exploring the experiences that support the development of allyship, as well as the barriers that men face. Understanding the reasons why some men are reluctant to be allies could assist organizations in creating effective gender-equity programs. Second, research is needed around understanding the mindsets of male leaders towards allyship, effective strategies to change reluctant mindsets to support allyship, and the role of organizational culture in the willingness of men to be allies. Finally, the current study drew its population from a socially conservative geographic area where the respondents were predominately White, which is consistent with other male ally studies. Future research should look at a more representative cross-section of men, as well as explore the impact of intersectionality on being a male ally.

Past research has clearly shown that organizations of all kinds will increasingly thrive when both men and women hold management and leadership roles and work together (Madsen, 2017). Yet, this will not happen unless more men become thoughtful, strategic allies for women. As we join forces to improve the status of women in organizational, local, region, country, and global arenas, we will strengthen the positive impact of both women and men in their organizations and communities around the world. 


\section{References}

Anicha, C. L., Burnett, A., \& Bilen-Green, C. (2015). Men faculty gender-equity advocates: A qualitative analysis of theory and praxis. The Journal of Men's Studies, 23(1), 21-43.

Badaracco, J. L. (1997). Defining moments: When managers must choose between right and right. Boston, MA: Harvard Business Review Press.

Bennis, W., \& Thomas, R. J. (2002, September). Crucibles of leadership. Harvard Business Review. Retrieved from https://hbr.org/2002/09/crucibles-of-leadership

Bierema, L. L (2017). No woman left behind: Critical leadership development to build gender consciousness and transform organizations. In S. R. Madsen (Ed.), Handbook of research on gender and leadership (pp. 145-162). Cheltenham, UK: Edward Elgar Publishing.

Bowers, K. (2016, February 17). Men as allies. Working Mother. Retrieved from https://www.workingmother.com/men-as-allies

Carter N. M. \& Silva, C. (2010, March). Women in management: Delusions of progress. Harvard Business Review. Retrieved from https://hbr.org/2010/03/women-in$\underline{\text { management-delusions-of-progress/ar/1 }}$

Casey, E. A., Carlson, J., Fraguela-Rios, C., Kimball, E., Neugut, T. B., Tolman, R. M., \& Edleson, J. L. (2013). Context, challenges, and tensions in global efforts to engage men in the prevention of violence against women: An ecological analysis. Men and Masculinities, 16(2), 228-251.

Catalyst Information Center. (2013). Why diversity matters. Catalyst. Retrieved from http://www.catalyst.org/knowledge/why-diversity-matters

Center for Women and Business. (2017). Men as allies: Engaging men to advance women in the workplace. Waltham, MA: Bentley University. Retrieved from 
https://www.bentley.edu/files/2017/05/02/CWB\%20Men\%20as\%20Allies\%20Research \%20Report \%20Spring\%202017.pdf

Cheng, S., Ng, L., Trump-Steele, R. C., Corrington, A., \& Hebl, M. (2018). Calling on male allies to promote gender equity in IO psychology. Industrial and Organizational Psychology, 11(3), 389-398.

Cleaver, J. (2016, October 24). Short article: Should men advocate for more female leaders? SAGE business researcher. doi: 10.1177/237455680221.n6, Retrieved from http://businessresearcher.sagepub.com/

Clerkin, C., \& Wilson, M. S. (2017). Gender differences in developmental experiences. In S. R. Madsen (Ed.), Handbook of research on gender and leadership (pp. 378-394). Cheltenham, UK: Edward Elgar Publishing.

Creswell, J. W. (2012). Educational research: Planning, conducting, and evaluating quantitative and qualitative research. (4th ed.). Boston: Pearson.

Czopp, A. M., \& Monteith, M. J. (2003). Confronting prejudice (literally): Reactions to confrontations of racial and gender bias. Personality and Social Psychology Bulletin, $29(4), 532-544$.

Debebe, G., Anderson, D., Bilimoria, D., \& Vinnicombe, S. M. (2016). Women's leadership development programs: Lessons learned and new frontiers. Journal of Management Education, 40(3), 231-252.

Drury, B. J., \& Kaiser, C. R. (2014). Allies against sexism: The role of men in confronting sexism. Journal of Social Issues, 70(4), 637-652. 
DuBow, W. M., \& Ashcraft, C. (2016). Male allies: Motivations and barriers for participating in diversity initiatives in the technology workplace. International Journal of Gender, Science and Technology, 8(2), 160-180.

Ely, R. J., Ibarra, H., \& Kolb, D. M. (2011). Taking gender into account: Theory and design for women's leadership development programs. Academy of Management Learning \& Education, 10(3), 474-493.

Evans, N. J., \& Wall, V. A. (Eds.). (1991). Beyond tolerance: Gays, lesbians and bisexuals on campus. Alexandria, VA: American Association for Counseling and Development.

Hewlett, S. A. (2013). Forget a mentor, find a sponsor: The new way to fast-track your career. Boston, MA: Harvard Business Review Press.

Hezlett, S. A. (2016). Enhancing experience-driven leadership development. Advances in Developing Human Resources, 18(3), 369-389.

Johnson, B. W., \& Smith, D. G. (2018, October 12). How men can become better allies to women. Harvard Business Review. Retrieved from https://hbr.org/2018/10/how-men-canbecome-better-allies-to-women

Johnson, S. J., Blackman, D. A., \& Buick, F. (2018). The 70: 20: 10 framework and the transfer of learning. Human Resource Development Quarterly, 29(4), 383-402.

Krentz, M., Wierzba, O., Abouzahr, K., Garcia-Alonso, J., \& Taplett, F. B. (2017). Five ways men can improve gender diversity at work. Boston, MA: Boston Consulting Group.

Madsen, S. R. \& Scribner, R. T. (2017). A perspective on gender in management: The need for strategic cross-cultural scholarship on women in management and leadership. Cross Cultural \& Strategic Management, 24(2), pp. 231-250. doi: 10.1108/CCSM-05-20160101 
Madsen, S. R. (2008a). Developing leadership: Learning from the experiences of women governors. New York, NY: University Press of America, Inc.

Madsen, S. R. (2008b). On becoming a woman leader: Learning from the experiences of university presidents. San Francisco, CA: John Wiley \& Sons, Inc.

Madsen, S. R. (2009). Transformational learning experiences of female UAE college students. Education, Business, and Society: Contemporary Middle Eastern Issues, 2(1), 20-31. doi.org/10.1108/17537980910938451

Madsen, S. R. (Ed.) (2017). Handbook of research on gender and leadership. Cheltenham, UK: Edward Elgar Publishing.

Madsen, S. R., Townsend, A. \& Scribner, R. T. (2018, October 3). What male allies can do to strengthen the impact of Utah women in workplace settings. Research \& Policy Brief, Utah Women \& Leadership Project. Retrieved from https://www.uvu.edu/uwlp/docs/whatcanidomaleallies.pdf

McCall, M. W., Lombardo, M. M., \& Morrison, A. M. (1988). Lessons of experience: How successful executives develop on the job. New York, NY: The Free Press.

McCauley, C. D., \& McCall Jr, M. W. (2014). Using experience to develop leadership talent: How organizations leverage on-the-job development. San Francisco, CA: John Wiley \& Sons.

Ngunjiri, F. W., \& Gardner, R. (2017). Future strategies for developing women as leaders. In S. R. Madsen (Ed.), Handbook of research on gender and leadership (pp. 423-437). Cheltenham, UK: Edward Elgar Publishing. 
Peretz, T. (2018). Seeing the invisible knapsack: Feminist men's strategic responses to the continuation of male privilege in feminist spaces. Men and Masculinities, 1-29. doi: $10.11777 / 1097184 X 18784990$

Piccigallo, J. R., Lilley, T. G., \& Miller, S. L. (2012). "It's cool to care about sexual violence”: Men's experiences with sexual assault prevention. Men and Masculinities, 15(5), 507525.

Prime, J., \& Moss-Racusin, C. A. (2009). Engaging men in gender initiatives: What change agents need to know. New York, NY: Catalyst.

Rasinski, H. M., \& Czopp, A. M. (2010). The effect of target status on witnesses' reactions to confrontations of bias. Basic and Applied Social Psychology, 32(1), 8-16.

Sawyer, K., \& Valerio, A. M. (2018). Making the case for male champions for gender inclusiveness at work. Organizational Dynamics, 47(1), 1-7.

Scribner, R. T. \& Madsen, S. R. (2018). What male allies can do to strengthen the impact of Utah women in workplace settings. Utah Women \& Leadership Project, Retrieved from https://www.uvu.edu/uwlp/docs/whatcanidomaleallies.pdf

Sherf, E. N., Tangirala, S., \& Weber, K. C. (2017). It is not my place! Psychological standing and men's voice and participation in gender-parity initiatives. Organization Science, 28(2), 193-210.

Smith, D. G., \& Johnson, W. B. (2017, October 13). Lots of men are gender-equality allies in private: Why not in public. Harvard Business Review. Retrieved from https://hbr.org/2017/10/lots-of-men-are-gender-equality-allies-in-private-why-not-inpublic 
Storberg-Walker, J., \& Madsen, S. R. (2017, May 23). The women and leadership theory think tank report 2015. George Washington University. Retrieved from https://www.uvu.edu/uwlp/docs/wlthinktankreport2015.pdf

Sue, D. W. (2017). The challenges of becoming a White ally. The Counseling Psychologist, 45(5), 706-716.

Sugiyama, K., Cavanagh, K. V., van Esch, C., Bilimoria, D., \& Brown, C. (2016). Inclusive leadership development drawing from pedagogies of women's and general leadership development programs. Journal of Management Education, 40(3), 253-292.

Swim, J. K., \& Thomas, M. A. (2006). Responding to everyday discrimination: A synthesis of research on goal-directed, self-regulatory coping behaviors. In S. Levin \& C. Van Laar, Stigma and group inequality: Social Psychological Perspectives (pp. 119-140). New York, NY: Psychology Press.

Van Velsor, E., \& Hughes, M. W. (1990). Gender differences in the development of managers: How women managers learn from experience (technical report). Greensboro, NC: Center for Creative Leadership.

Van Velsor, E., Wilson, M., Criswell, C., \& Chandrasekar, N. A. (2013). Learning to lead: A comparison of developmental events and learning among managers in China, India and the United States. Asian Business \& Management, 12(4), 455-476.

Warner, J., \& Corley, D. (2017, May 21). The women's leadership gap: Women's leadership by the numbers. Retrieved from https://www.americanprogress.org/issues/women/reports/2017/05/21/432758/womensleadership-gap/ 
Yip, J., \& Wilson, M. S. (2010). Learning from experience. In E. Van Velsor, C. D. McCauley, \& M. N. Ruderman, The Center for Creative Leadership handbook of leadership development (pp. 63-95). San Francisco, CA: Jossey-Bass. 
Table 1. Primary Themes and Descriptions

\begin{tabular}{|c|c|}
\hline Themes & Description \\
\hline $\begin{array}{l}\text { Addressing Gendered } \\
\text { Perceptions \& Biases }\end{array}$ & $\begin{array}{l}\text { Increase awareness of how gender impacts women's } \\
\text { work experiences, see advancement of women as an } \\
\text { organizational issue, and call out bullying and } \\
\text { patronizing behaviors that subordinate women. }\end{array}$ \\
\hline $\begin{array}{l}\text { Challenging Gender } \\
\text { Discrimination }\end{array}$ & $\begin{array}{l}\text { Become proactive in recognizing and working to } \\
\text { eliminate all forms of discriminatory and sexist } \\
\text { behavior; understand that such experiences can be } \\
\text { pervasive and deeply troubling for many women, } \\
\text { which can impact their self-confidence. }\end{array}$ \\
\hline Developmental Relationships & $\begin{array}{l}\text { Intentionally mentor, support, encourage, and advocate } \\
\text { for women in the workplace. }\end{array}$ \\
\hline Fairness Is Key & $\begin{array}{l}\text { Provide to women the same opportunities that are } \\
\text { offered to men, including mentoring and } \\
\text { developmental assignments; support healthy work-life } \\
\text { balance for all employees. }\end{array}$ \\
\hline HR Processes & $\begin{array}{l}\text { Proactively include women candidates in all hiring and } \\
\text { promotion opportunities, ensure gender balance on } \\
\text { hiring committees, and monitor wages for pay equity. }\end{array}$ \\
\hline $\begin{array}{l}\text { Leadership \& Professional } \\
\text { Development }\end{array}$ & $\begin{array}{l}\text { Identify "stretch" assignments that provide women } \\
\text { visibility to executive leaders, encourage women to } \\
\text { pursue additional education, and support women } \\
\text { receiving leadership development training. }\end{array}$ \\
\hline Looking to the Long Game & $\begin{array}{l}\text { Intentionally expose women to business operations and } \\
\text { management decisions, assign women to chair } \\
\text { committees and task forces, and set expectations that } \\
\text { women have a place in leadership. }\end{array}$ \\
\hline Raising Awareness & $\begin{array}{l}\text { Make deliberate efforts to help more men understand } \\
\text { barriers many professional women face; encourage } \\
\text { open dialogue and a willingness to change perceptions } \\
\text { and behaviors. }\end{array}$ \\
\hline Recognition & $\begin{array}{l}\text { Recognize (both publicly and privately) the efforts and } \\
\text { contributions of women, including their ideas and work } \\
\text { products; actively include women's voices in } \\
\text { discussions and decisions. }\end{array}$ \\
\hline Treating Women as Equals & $\begin{array}{l}\text { Call out gendered biases and assumptions; initiate } \\
\text { conversations about unconscious bias and its impact in } \\
\text { the workplace. }\end{array}$ \\
\hline
\end{tabular}

